\title{
Facial nerve paralysis and partial brachial plexopathy after epidural blood patch: a case report and review of the literature
}

This article was published in the following Dove Press journal:

Journal of Pain Research

I February 201 I

Number of times this article has been viewed

\author{
Radi Shahien \\ Abdalla Bowirrat \\ Department of Neurology, \\ Ziv Medical Center, Zfat, Israel
}

Correspondence: Radi Shahien Department of Neurology, Ziv Medical Center, Zfat, I3100, Israel

Tel $+97246828927 / 8$

Fax +97246828648

Email shahien.r@ziv.health.gov.il
Abstract: We report a complication related to epidural analgesia for delivery in a 24 -year-old woman who was admitted with mild pre-eclampsia and for induction of labor. At the first postpartum day she developed a postdural puncture headache, which was unresponsive to conservative measures. On the fifth day an epidural blood patch was done, and her headache subsided. Sixteen hours later she developed paralysis of the right facial nerve, which was treated with prednisone. Seven days later she complained of pain in the left arm and the posterior region of the shoulder. She was later admitted and diagnosed with partial brachial plexopathy.

Keywords: facial nerve paralysis, partial brachial plexopathy, epidural blood patch

\section{Case report}

A 24-year-old woman with mild pre-eclampsia was admitted for induction of labor under normal-term labor after 40 weeks' gestation. Ten days before her admission she was admitted for 6 days for mild hypertension and moderate edema of her legs. The patient was afebrile and her general examination was normal. Neurological examination showed a fully conscious patient. Her blood pressure at the time of admission was 152/82 mm Hg and her heart rate was 86 and regular. Blood analyses disclosed normal hepatic and renal function. Electrolyte and hematological and coagulation tests were normal. Electrocardiogram and chest X-ray were also normal.

Labor was induced with intravaginal prostaglandin on the second day of admission. The patient requested epidural analgesia, and an epidural catheter was inserted successfully at the L3-4 interspace through an 18-gauge Tuohy needle. Sensory anesthesia was established with $8 \mathrm{~mL}$ of $0.25 \%$ bupivacaine and $0.1 \mathrm{~mL}$ of fentanyl. The patient underwent vaginal delivery of a $3365 \mathrm{~g}$ female infant with an Apgar score of 9. After delivery, the epidural anesthesia was stopped by the anesthesiologist, who removed the epidural catheter from the patient's back.

One day after the delivery the patient developed a postdural puncture headache (PDPH), which was managed by conservative measures: bed rest (patient's position of choice), increased hydration (normal saline $3 \mathrm{~L}$ per day intravenously), and metamizole sodium (Dipyrone ${ }^{\circledR}$; Garan S.K. Ltd, Ramat Gan, Israel) $500 \mathrm{mg}$ three times per day, which is commonly used in many countries as a powerful analgesic and antipyretic. Despite the conservative treatment, the patient's condition did not improve. Her headache worsened when she was in an upright position and was relieved when she was lying flat. On the fifth postpartum day, an epidural blood patch (EBP) was recommended. This was performed at one level above the epidural anesthesia, with 
$18 \mathrm{~mL}$ of autologous blood taken from the antecubbital vein. The headache improved immediately.

Sixteen hours later she developed paralysis of lower motor neuron type of her right facial nerve, which was treated with prednisone at a dosage of $50 \mathrm{mg}$ daily for 5 days, tapering off by $10 \mathrm{mg} /$ day for an additional 5 days. Resolution of the patient's symptoms and complete recovery of the seventh nerve was observed after 9 days. Six days after application of the EBP, a nerve conduction study (NCS) of the seventh cranial nerve and blink reflexes was performed; these tests showed normal findings. Seven days after the application of the EBP, the patient suffered pain in the posterior shoulder and in the left arm mainly posteriorly, which was mildly burning and increased gradually over several days. Three weeks after the EBP she was admitted to the neurological department after complaining of continuous pain. Her neurological examination revealed a severe weakness with moderate atrophy of the left infraspinatous muscle (Figure 1). One day after admission (22 days after application of the EBP), a magnetic resonance imaging (MRI) scan of the brain and cervical spine region showed normal findings of the brain but a spread of the EBP (trace amounts of blood) in the cervical spine region. An electromyography performed 23 days after showed spontaneous activity (positive sharp waves) and active denervation in the left infraspinatus, and a mild neurogenic pattern in the supraspinatus on the same side (Figure 2 and Figure 3). NCS of the suprascapular nerve, which arises from the trunk and is formed by the union of the fifth and sixth cervical nerves and innervates the supraspinatus and infraspinatus muscles, revealed no response in the infraspinatus division (Figure 4). An NCS of the bilateral median and ulnar nerves as well as the right peroneal, right tibial,

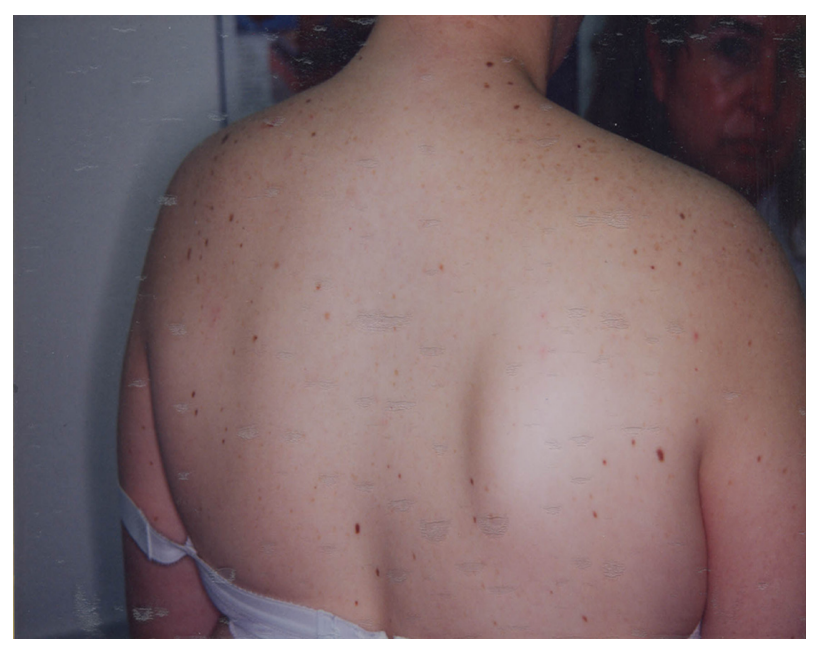

Figure I Moderate atrophy of the left infraspinatous muscle. and right surral nerves was normal. Physiotherapy of the affected muscle was recommended, and this resulted in mild improvement over 3 months.

\section{Introduction}

Dural puncture is a commonly performed invasive procedure for various medical indications like diagnostic lumbar puncture, spinal anesthesia, myelography, and intrathecal chemotherapy. However, in anesthesiology, apart from intentional dural puncture as in spinal anesthesia, unintentional dural puncture can also occur while performing epidural anesthesia or analgesia for various indications, including postoperative and labor pain relief.

EBP is a treatment procedure for PDPH and refers to the injection of 15-20 mL of a patient's autologous blood into the epidural space of the vertebral column at or near the location of a dural puncture. The first report of blood patch ${ }^{1}$ used only 2-3 mL. Using this small volume, had the blood clot formed in a position that did not seal the dural tear, the benefits of blood patching may not have been evident. Since that time, the need for adequate volumes of blood has been emphasized. Crawford $^{2}$ recommended the injection of $20 \mathrm{~mL}$ of blood (but less if there is discomfort). Lower volumes were found to have a higher failure rate. Ostheimer et $\mathrm{al}^{3}$ and Abouleish et $\mathrm{al},{ }^{4}$ however, found that volumes of less than $10 \mathrm{~mL}$ were associated with higher initial failure or recurrence of PDPH after initial apparent success.

The volume injected displaces cerebrospinal fluid (CSF) from the lumbar CSF space into the area surrounding the brain, often yielding immediate headache relief. When the blood clots it seals the dural puncture, prohibiting further leakage of CSF from the subarachnoid space.

When headache appears in the postoperative or postpartum period after regional anesthesia, it can have many causes, apart from a complication of dural puncture during regional anesthesia. However, the most common cause of an anesthesiainduced headache is PDPH. Historically, PDPH was described firstly by Karl August Bier in $1899,{ }^{5}$ when he gave the first spinal anesthetic, injecting $10-15 \mathrm{mg}$ of cocaine to seven patients, himself, and his assistant. ${ }^{5}$ Dr Bier described the headache as a feeling of very high pressure in the head, accompanied by light dizziness when rising quickly from the chair. He also described the most important sign of PDPH as follows: "all symptoms disappeared immediately when I laid horizontally but came back when I got upright". 5 Dr Biers suggested that CSF loss caused the symptoms he experienced, and he recommended preventing the loss of CSF as much as possible. He lost excessive CSF while receiving the experimental spinal block from his assistant, who 


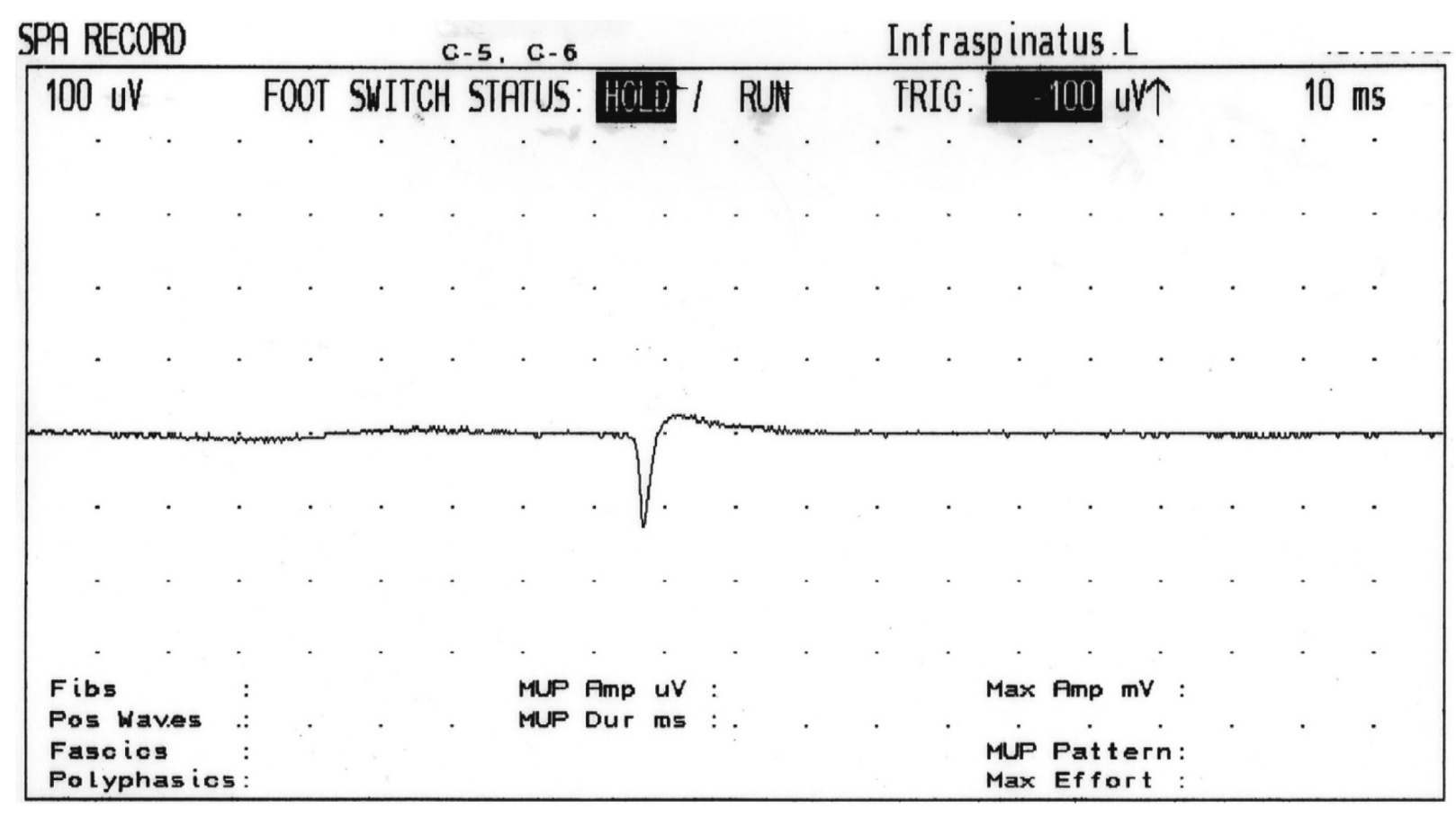

Figure 2 Electromyography shows spontaneous activity and active denervation in the left infraspinatus muscle.

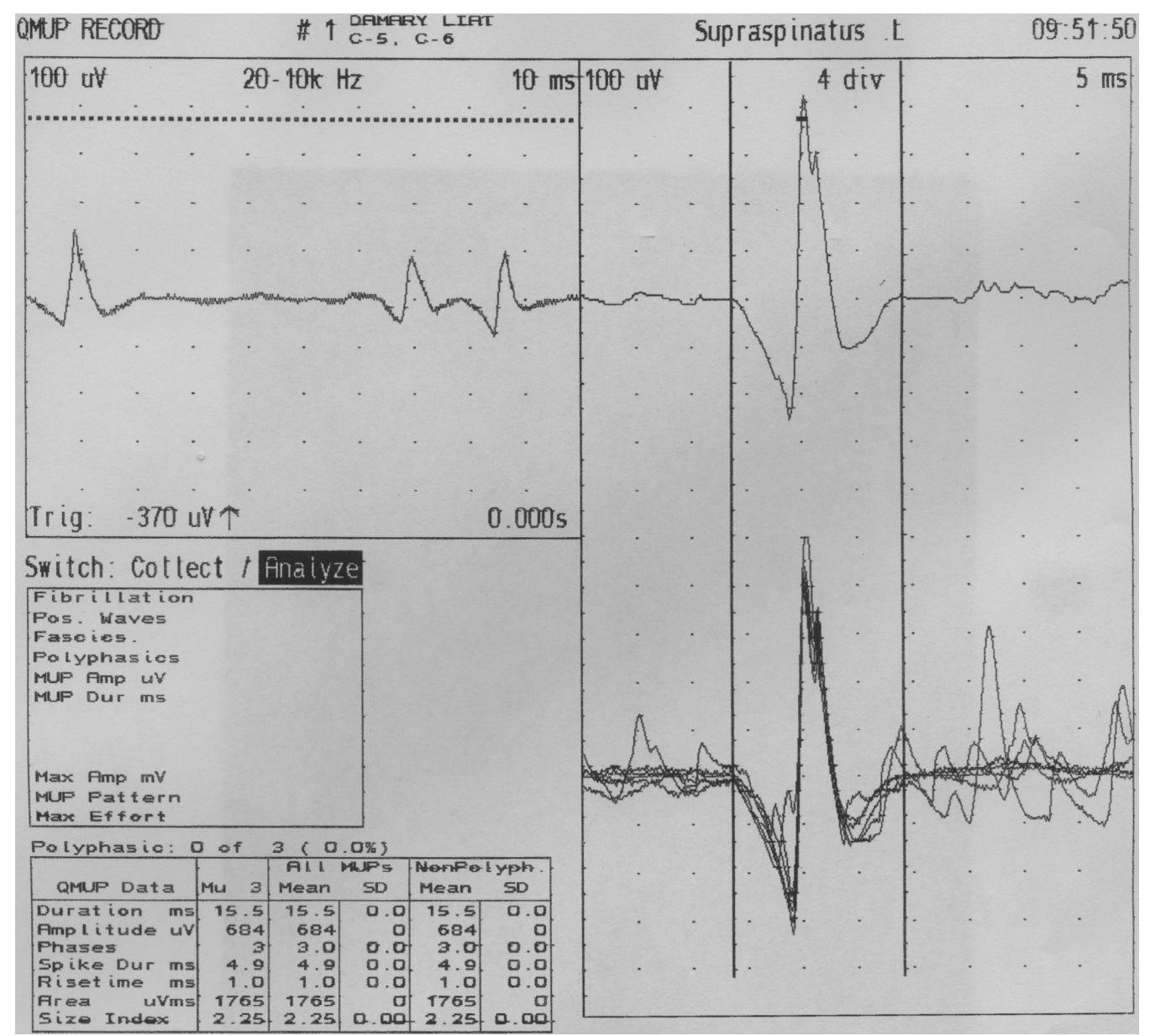

Figure 3 Electromyography shows a mild neurogenic pattern in the supraspinatus on the left side. 


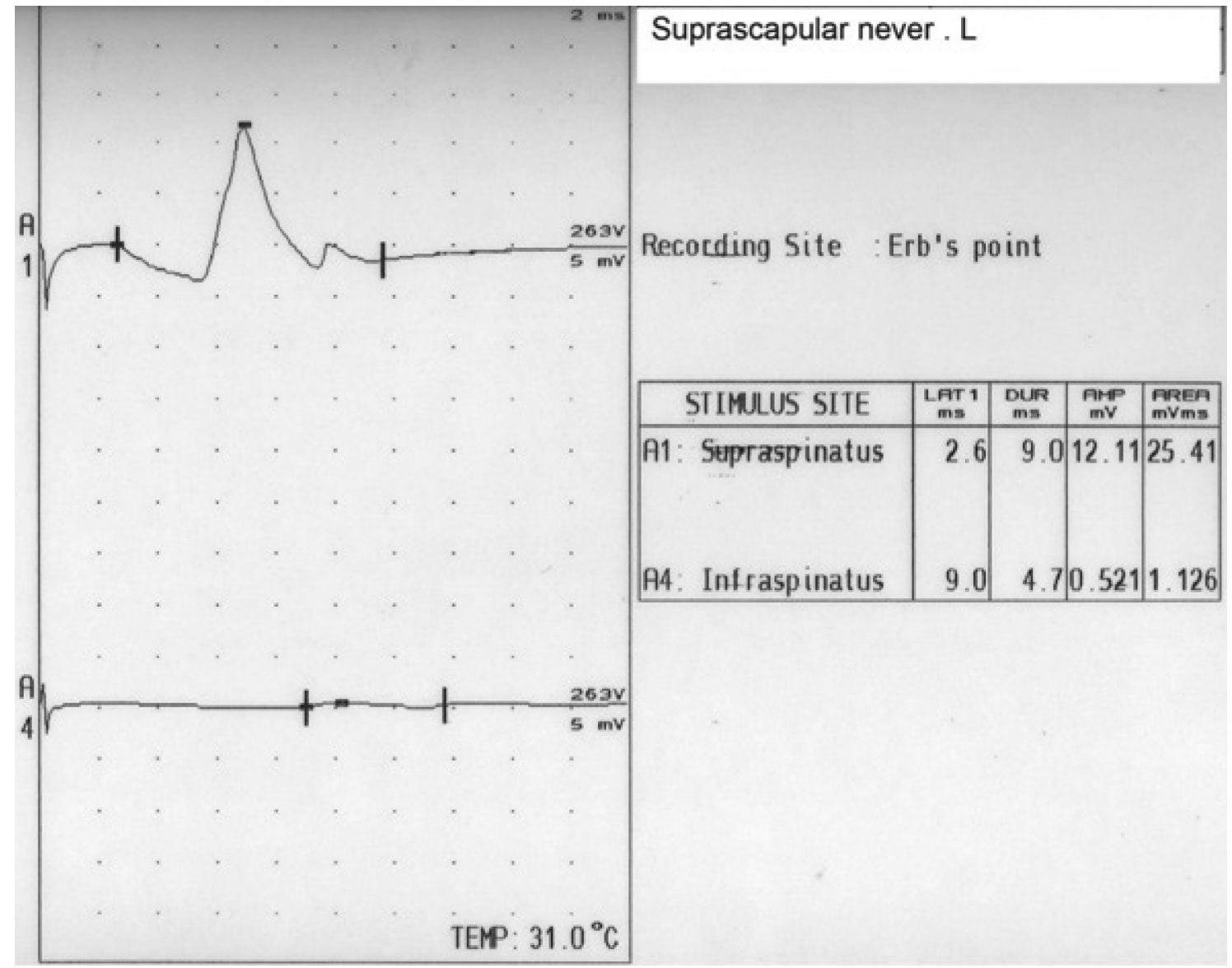

Figure $4 \mathrm{~A}$ nerve conduction study of the left suprascapular nerve reveals no response in the infraspinatus division.

was unable to fit the syringe to the needle during the procedure. ${ }^{5}$ Indeed, PDPH typically occurs hours to days after puncture and presents with symptoms such as headache and nausea that typically worsen when the patient assumes an upright posture. It is thought to result from a loss of CSF into the epidural space. ${ }^{6-9}$ Decreased hydrostatic pressure in the subarachnoid space then leads to traction to the meninges with associated symptoms.

Diagnosis of PDPH depends on its association with body position; the pain is aggravated by sitting or standing and relieved or decreased by lying down flat. ${ }^{10,11}$ Headache after dural puncture is a complication of spinal anesthesia and is believed to result from leakage of CSF at the time of dural puncture and, probably more importantly, continued leaking afterwards. ${ }^{12,13}$ Criteria of $\mathrm{PDPH}^{14}$ are summarized by the following characteristics: occurred after mobilization; aggravated by an erect or a sitting position and coughing, sneezing, or straining; and relieved by lying flat. PDPH is mostly localized and classified as occipital, frontal, or generalized.

Epidemiologically, PDPH occurs in $10 \%-40 \%$ of patients who have a lumbar puncture. The overall incidence of PDPH after intentional dural puncture varies from $0.1 \%$ to $36 \%$.
The highest incidence of $36 \%$ was reported after ambulatory diagnostic lumbar puncture using a 20- or 22-gauge standard Quincke spinal needle. ${ }^{15,16}$ Unintentional dural puncture with a large Tuohy needle (16 and 18 gauge) is associated with a high incidence of $70 \%-80 \%$ PDPH.

In an obstetric population, unintentional dural puncture is one of the most common major complications. Indeed, there is considerable variability in the incidence of PDPH, which is affected by many factors, including age, gender, needle size, and needle type. A prospective review of 100 parturients from Australia who experienced accidental dural puncture with a Tuohy needle had a PDPH rate of $81 \% .{ }^{17}$ The diagnosis of dural puncture was delayed until presentation of headache in $27 \%$ of these cases. A similar incidence of PDPH has been found by other investigators, ${ }^{18-20}$ but Choi et al ${ }^{10}$ performed a meta-analysis of obstetrical studies and reported that the pooled risk for accidental dural puncture for all epidural needles was $1.5 \%$. Once dural puncture occurred, the risk of PDPH was $52.1 \%$. The risk of PDPH varied amongst spinal needles and ranged from $1.5 \%$ to $11.2 \% .{ }^{10}$ The effectiveness and early reports of the EBP procedure demonstrated that 
immediate and permanent cure rates approached 100\%. In this study, we describe an unfamiliar neurological complication of epidural analgesia during labor, the development of facial nerve palsy and partial brachial plexopathy, which, to our knowledge, has not been previously reported. We received a written consent form from our patient.

\section{Discussion}

This case report is a distinctive neurological complication of epidural analgesia during labor. We could not find a similar case of brachial plexopathy reported in the literature as a complication of EBP. Here, we report a unique case of facial paralysis and neuralgic amyotrophy of the suprascapular nerve suspected to be secondary to the EBP.

Various neurological consequences following dural puncture are well recognized. ${ }^{5}$ The most serious rare complication is the occurrence of transient cranial nerves palsy, and almost all cranial nerves have been implicated. ${ }^{20}$ Usually, single nerve palsy has been reported, with the nerves affected being the third, fourth, sixth, seventh, and eighth..$^{20} \mathrm{~A}$ reported incidence of cranial nerve palsies is $1: 100,000$ to $3.7: 100,000 .{ }^{20}$ The sixth nerve is said to be most susceptible, but length alone is not the sole factor, as the fourth cranial nerve is longer than the sixth cranial nerve but is rarely affected. ${ }^{1}$ The abducent nerve is suggested to be vulnerable because it is relatively fixed at its entry into the cavernous sinus and at its attachment to the pons. This nerve is most likely to be stretched due to sagging of the brain because of a CSF leak. ${ }^{1}$

Facial nerve palsy associated with EBP was first reported by Abouleish et al in $1975 .{ }^{4}$ The paralysis in their patient occurred 4 days after EBP was performed and was considered a coincidence. ${ }^{2,21}$ Fang et al, ${ }^{22}$ in 2010, presented a case of a 29-year-old woman who underwent an emergency cesarean section due to a prolonged second stage of labor and suffered trigeminal nerve and facial nerve palsy after combined spinal-epidural anesthesia. ${ }^{22}$

Population-based epidemiologic studies have demonstrated an increased incidence more than three-fold that of of Bell's palsy during pregnancy, especially in the third trimester and the early postpartum period..$^{4,23-25}$ The etiology of Bell's palsy is unknown, ${ }^{13,24}$ although two theories exist. The speculated causes are either edema or viral manifestation. ${ }^{25,26}$ The edema hypothesis postulates that fluid retention and generalized edema of pregnancy result in a compression of the facial nerve with resulting facial paralysis. ${ }^{13,26}$ This view is supported by the high incidence of Bell's palsy during the time of maximal fluid retention in the third trimester. There seems to be an association between Bell's palsy and hypertensive disorders during pregnancy that often leads to increased fluid retention and the higher frequency of other nerve compression manifestations such as carpel tunnel syndrome. ${ }^{15}$ Support for the viral causation includes the fact that patients with Bell's palsy have evidence of previous herpes virus infection; the presence of pregnancy-induced immunosuppressant, which may predispose to reactivation of a latent herpes virus within the nerve ganglia; the fact that Bell's palsy syndrome is sometimes part of a complex cranial polyneuritis, ${ }^{16}$ with the presence of lymphocytosis and increased protein in the CSF of the affected patients; and occurrence of clusters or epidemics of Bell's palsy. There is controversy concerning the relationship between Bell's palsy and pre-eclampsia. ${ }^{17}$ Notwithstanding the different neurological complications known in the pre-eclampsia period as PDPH and cranial subdural haematoma associated with dural puncture in labor, peripartum cardiomyopathy, anesthesia after cesarean delivery, and seizures, our patient did not demonstrate any facial weakness after the PDPH period. The paralysis was noticed just after the EBP and cessation of the PDPH. In addition, blood injected into the epidural space ascends in the spinal column, and trace amounts get to the cervical spine region, as shown by MRI scans post-EBP. Certainly, some inflammation often occurs in the epidural space, but typically this is manifested in lumbar/sacral symptoms and not cervical, although Horner's syndrome does occasionally occur with large epidural top-ups. ${ }^{27}$ This suggests a pathophysiological cause different from the loss of CSF, inflammation, or Horner's syndrome. Previous reports have postulated that a sudden increase in intracranial pressure caused by a blood patch may compromise the blood supply to the seventh nerve within the facial canal. ${ }^{21,22}$ An increase in the epidural and subarachnoid pressure secondary to injection of blood volume in the epidural space has been described. ${ }^{18}$

In a recent study, Boezaar ${ }^{28}$ proposed that PDPH is probably a vascular-type headache and that an EBP relieves the headache by its vasoconstrictive action. ${ }^{29}$ This cerebral vasoconstriction may be caused by subarachnoid spread of the injected blood. Indeed, low CSF pressure results in cerebrovascular vasodilatation and headache that is similar in mechanism to other vascular headaches such as migraine. ${ }^{30} \mathrm{In}$ addition, the possible role that the rich innervations of the dura matter with adrenergic, cholinergic, and peptidergic fibers may play in PDPH and its management with an EBP require further research to know the exact mechanism of PDPH. Other hypotheses include the delay in EBP performance that may have led to the patient's symptoms. In other words, rather than 
the EBP causing the facial and brachial symptoms, perhaps an earlier EBP may have prevented its occurrence. ${ }^{31}$

The possibility of accidental epidural injection of anesthetic should be considered. Accidental production of spinal anesthesia has been reported as a complication of attempted brachial plexus blockade using the posterior approach of brachial plexus blockade, which may indicate that there is a possible pathway that fluid (either blood or local anesthetic) can traverse between the epidural space and the brachial plexus roots or trunks. In fact, the tip of the block needle may have entered a dural cuff that can run with a nerve root for some distance from the intervertebral foramen, in the end causing brachial plexus palsy. ${ }^{32-34}$

The course and succession of events in our case study have special characteristics, such as the rapid resolution of the patient's symptoms and the complete recovery of the seventh nerve, which was observed after only 9 days. This speedy recovery has not been encountered among patients suffering from Bell's palsy, where improvement is gradual and recovery times vary. With or without treatment, most individuals begin to get better within 2 weeks after the initial onset of symptoms and most recover completely, returning to normal function within 3-6 months. Also, we do not exclude the hypothesis of irritation of the nerve roots due to the spread of blood as an etiology of our case.

The suprascapular nerve derived from the upper trunk of the brachial plexus, typically receiving fibers from $\mathrm{C} 5$ and C6, contains both motor and sensory components and sends sensory branches to both the glenohumeral and acromioclavicular joints but does not innervate the skin. It passes downward laterally (deeply to the omohyoid and trapezius and then posteriorly to run under cover of trapezius) along with the suprascapular vein and artery. It reaches the suprascapular notch, then the nerve travels beneath the suprascapular notch, whereas the vessels travel above the notch; after giving off two branches to supraspinatus, it passes around the lateral border of the scapular spine (spinoglenoid notch) and ends in the infraspinatus fossa to supply infraspinatus. Peripheral nerves are highly susceptible to injury from stretching and compression. Both of these mechanisms result in nerve ischemia, edema, microenvironmental changes, and conduction impairment. These changes are proportional to the magnitude and duration of the insult and eventually lead to irreversible damage. ${ }^{35,36}$ Indeed, the suprascapular nerve may be injured as a result of trauma, repetitive overuse, a mass lesion, or iatrogenic causes. Traumatic causes of suprascapular nerve injury include scapular fractures, ${ }^{37}$ clavicular fractures, ${ }^{38}$ shoulder dislocations, ${ }^{39}$ and penetrating trauma. ${ }^{40}$ Also, iatrogenic injury to the suprascapular nerve may occur during operative procedures. ${ }^{41,42} \mathrm{~A}$ common location for injury to the suprascapular nerve is the suprascapular notch. The mechanism by which injury occurs at the suprascapular notch has been termed "the sling effect" by Rengachary et al..$^{43}$ They evaluated the motion of the suprascapular nerve relative to the suprascapular notch with various movements of the arm and shoulder. They noted that the nerve was often opposed to the sharp inferior margin of the superior transverse scapular ligament and that the contact was accentuated with depression and retraction, or hyperabduction, of the shoulder.

The spinoglenoid notch is another site where the suprascapular nerve is frequently injured. ${ }^{44}$ Several hypotheses have been proposed regarding the etiology of this injury. One theory is that the nerve is compressed in the fibro-osseous tunnel formed by the spine of the scapula and a hypertrophied spinoglenoid ligament. Other hypotheses have expressed the belief that the nerve is injured as a result of the anatomy of the spinoglenoid notch and stress that is placed on the nerve by repetitive overhead activities. This theory is supported by clinical data that show that the majority of these injuries occur in athletes who repetitively stress their shoulder. A large percentage of the cases that have been reported were in professional volleyball players. ${ }^{45}$ Another hypothesis is that the nerve is compressed between the spine of the scapula and the medial tendinous margin of the infraspinatus and supraspinatus muscles during extreme abduction of the shoulder with full external rotation. ${ }^{46,47}$ It has been proposed that stretching of the suprascapular artery during pitching results in intimal damage to the suprascapular artery. Microthrombi form and embolize to the vasa nervorum of the suprascapular nerve with resultant ischemic damage. However, to our knowledge there are no scientific data to support this theory.

Another mechanism by which the suprascapular nerve may be injured is compression by a mass, most commonly a ganglion cyst. Other masses that have been described include synovial sarcoma, Ewing's sarcoma, chondrosarcoma, metastatic renal cell carcinoma, and a bone cyst. ${ }^{48}$

\section{Disclosure}

The authors report no conflicts of interest in this work.

\section{References}

1. Gormley JB. Treatment of post-spinal headache. Anesthesiology. 1960;21:565-566.

2. Crawford JS. Experiences with epidural blood patch. Anaesthesia. 1980;35:513-515.

3. Ostheimer GW, Palahniuk RJ, Schnider SM. Epidural blood patch for post-lumbar puncture headache. Anesthesiology. 1974;41:307-308.

4. Abouleish E, Dela Vega S, Bleninger I, Tiong-Oen T. Long-term follow-up of epidural blood patch. Anesth Analg. 1975;54:459-463. 
5. Versuche BA. Uber cocainisierung des rucken markes. Deutsch Zeitschrift fur Chirurgie. 1899;51:361-369.

6. Bezov D, Lipton RB, Ashina S. Post-dural puncture headache: Part I diagnosis, epidemiology, etiology, and pathophysiology. Headache. 2010;50:1144-1152.

7. Grant R, Condon B, Hart I. Changes in intracranial CSF volume after lumbar puncture and their relationship to post-LP headache. $J$ Neurol Neurosurg Psychiatry. 1991;54:440-442.

8. Serpell MG, Rawal N. Headache after diagnostic dural punctures (editorial). BMJ. 2000;32:1973-1974.

9. Kunkle EC, Ray BS, Wolff HG. Experimental studies on headache: analysis of the headache associated with changes in intracranial pressure. Arch Neurol Psychiatry. 1943;49:323-358.

10. Choi PT, Galinski SE, Takeuchi L. PDPH rates onset and duration Can J Anaesth. 2003:50:460-469.

11. Garry M, Davies S. Failure of regional blockade for Caesarean section. Int J Obstet Anesth. 2002;11:9-12.

12. Kleinman W, Mikhail M. Spinal, epidural and caudal blocks. In: Morgan GE, Mikhail MS, Murray MJ. Clinical Anesthesiology. 4th ed 2006:319.

13. Vandam LD, Dripps RD. Long-term follow-up of patients who received 10,098 spinal anaesthetics. Syndrome of decreased intracranial pressure (headache and ocular and auditory difficulties). JAMA 1956;161:586-591.

14. Shah A, Bhatia PK, Tulsiani KL. Post dural puncture headach in caesarean section: a comparative study using $25 \mathrm{G}$ Quincke, $27 \mathrm{G}$ Quincke and 27 G Whitacre needle. Indian J Anaesth. 2002;46:373-377.

15. Mac Arthur C, Lewis M, Knox EG. Accidental dural puncture in obstetric patients and long-term symptoms. BMJ. 1993;306: 883-885.

16. Kuntz KM, Kohmen E, Steven JC, et al. Post lumbar puncture headache: experience in 501 consecutive procedure. Neurology. 1992;42:1884-1887.

17. Turnbill DK, Shepherd DB. Postdural puncture headache: pathogenesis, prevention and treatment. Br J Anaesth. 2003:91:718-729.

18. Cruickshank RH, Hopkins JM. Fluid flow through dural puncture sites. An in vitro comparison of needle point types. Anaesthesia. 1989;44: 415-418.

19. Costigan SN, Sprigge JS. Dural puncture: the patients perspective. A patient survey of cases at a DGH maternity unit 1983-1993. Acta Anaesthesiol Scand. 1996;40:710-714.

20. Reynolds F. Dural puncture and headache. BMJ. 1993;306:874-876.

21. Lowe DM, Mccullough AM. 7th nerve palsy after extradural blood patch. Br J Anaesth. 1990;65:721-722.

22. Fang JY, Lin JW, Li Q, et al. Trigeminal nerve and facial nerve palsy after combined spinal-epidural anesthesia for cesarean section. $J$ Clin Anesth. 2010;22:56-58.

23. Cooper G. Epidural blood patch. Eur J Anaesth. 1999;16:211-215.

24. Stride PC, Cooper GM. Dural taps re-visited. A 20 year survey from Birmingham Maternity Hospital. Anaesthesia. 1993;48:247-255.

25. Costigen SN, Sprigge JS. Dural puncture: the patient's perspective. A patient survey of cases at a DGH Maternity Unit (1983-1993). Acta Anaesthesiol Scand. 1996;40:710-714.

26. Lance JW, Branch GB. Persistent headache after lumbar puncture. Lancet. 1994;343:414.

27. Paw HGW. Horner's syndrome following low-dose epidural infusion for labour: a cautionary tale. Eur J Anaesth. 1998:15:110-111.

Journal of Pain Research

\section{Publish your work in this journal}

The Journal of Pain Research is an international, peer-reviewed, open access, online journal that welcomes laboratory and clinical findings in the fields of pain research and the prevention and management of pain. Original research, reviews, symposium reports, hypothesis formation and commentaries are all considered for publication.
28. Boezaart AP. Effects of cerebrospinal fluid loss and epidural blood patch on cerebral blood flow in swine. Reg Anesth Pain Med. 2001;26: 401-406.

29. Digiovanni AJ, Gilbert MW, Wahle WM. Epidural injection of autologous blood for post-lumbar puncture headache II. Additional clinical experience and laboratory investigation. Anesth Analg. 1972;51: 226-232.

30. Vernieri F, Moro L, Altamura C, et al. Patients with migraine with aura have increased flow mediated dilation. BMC Neurology. 2010;10: $10-18$.

31. Dunbar SA, Katz NP. Failure of delayed epidural blood patching to correct persistent cranial nerve palsies. Anesth Analg. 1994;79:806-807.

32. Aramideh M, van Der Oever HL, Walstra GJ, Dzoljic M. Spinal anesthesia as a complication of brachial plexus using the posterior approach. Anesth Analg. 2002;94:1338-1339.

33. Gomez RS, Mendes TCBS. Epidural anaesthesia complication of brachial plexus block. Anaesthesia. 2006;61:591-592.

34. Rettig HC, Gielen MJM, Jack NTM, et al. A comparison of the lateral and posterior approach of the brachial plexus. Reg Anesth Pain Med. 2006;31:119-126.

35. Lundborg G, Rydevik B. Effects of stretching the tibial nerve of the rabbit. A preliminary study of the intraneural circulation and the barrier function of the perineurium. J Bone and Joint Surg. 1973;55: 390-340.

36. Lundborg G. Structure and function of the intraneural microvessels as related to trauma, edema formation and nerve function. $J$ Bone and Joint Surg. 1975;57:938-948.

37. Edeland HG, Zachrisson BE. Fracture of the scapular notch associated with lesion of the suprascapular nerve. Acta Orthop Scandinavica. 1975;46:758-763.

38. Berry H, Kong K, Hudson AR, Moulton R. Isolated suprascapular nerve palsy: a review of nine cases. Canadian J Neurol Sci. 1995;22:301-304.

39. Travlos J, Goldberg I, Boome RS. Brachial plexus lesions associated with dislocated shoulders. J Bone and Joint Surg. 1990;72:68-71.

40. Weaver HL. Isolated suprascapular nerve lesions. Injury. 1983;15: 117-126.

41. De Mulder K, Marynissen H, van Laere C, et al. Arthroscopic transglenoid suture of Bankart lesions. Acta Orthop Belgica. 1998;64: 160-166.

42. Bigliani LU, Dalsey RM, McCann PD, April EW. An anatomical study of the suprascapular nerve. Arthroscopy. 1990;6:301-305.

43. Rengachary SS, Neff JP, Singer PA, Brackett CE. Suprascapular entrapment neuropathy: a clinical, anatomical, and comparative study. Part 1: clinical study. Neurosurgery. 1979:5:441-446.

44. Aiello I, Serra G, Traina GC, Tugnoli V. Entrapment of the suprascapular nerve at the spinoglenoid notch. Ann Neurol. 1982;12:314-316.

45. Cummins CA, Bowen M, Anderson K, Messer T. Suprascapular nerve entrapment at the spinoglenoid notch in a professional baseball pitcher. Am J Sports Med. 1999;27:810-812.

46. Sandow MJ, Ilic J. Suprascapular nerve rotator cuff compression syndrome in volleyball players. $J$ Shoulder and Elbow Surg. 1998;7: 516-521.

47. Ringel SP, Treihaft M, Carry M, et al. Suprascapular neuropathy in pitchers. Am J Sports Med. 1990;18:80-86.

48. Fritz RC, Helms CA, Steinbach LS, Genant HK. Suprascapular nerve entrapment: evaluation with MR imaging. Radiology. 1992;182: $437-444$.

\section{Dovepress}

The manuscript management system is completely online and includes a very quick and fair peer-review system, which is all easy to use. Visit http://www.dovepress.com/testimonials.php to read real quotes from published authors. 